\title{
Study of Prediagnostic Selenium Level in Toenails and the Risk of Advanced Prostate Cancer
}

\section{Citation}

Yoshizawa, Kazuko, Walter C. Willett, Steven J. Morris, Meir J. Stampfer, Donna Spiegelman, Eric B. Rimm, and Edward Giovannucci. 1998. "Study of Prediagnostic Selenium Level in Toenails and the Risk of Advanced Prostate Cancer." JNCl: Journal of the National Cancer Institute 90 (16): 1219-24. https://doi.org/10.1093/jnci/90.16.1219.

\section{Permanent link}

http://nrs.harvard.edu/urn-3:HUL.InstRepos:41263060

\section{Terms of Use}

This article was downloaded from Harvard University's DASH repository, WARNING: This file should NOT have been available for downloading from Harvard University's DASH repository.

\section{Share Your Story}

The Harvard community has made this article openly available.

Please share how this access benefits you. Submit a story.

Accessibility 


\section{REPORTS}

terval $[\mathrm{CI}]=0.25-0.96 ; P$ for trend $=$ .11). After additionally controlling for family history of prostate cancer, body mass index, calcium intake, lycopene intake, saturated fat intake, vasectomy, and geographical region, the $O R$ was $0.35(95 \% \mathrm{CI}=0.16-0.78 ; P$ for trend $=$ .03). Conclusions: Our results support earlier findings that higher selenium intakes may reduce the risk of prostate cancer. Further prospective studies and randomized trials of this relationship should be conducted. [J Natl Cancer Inst 1998;90:1219-24]

Background: In a recent randomized intervention trial, the risk of prostate cancer for men receiving a daily supplement of $200 \mu \mathrm{g}$ selenium was one third of that for men receiving placebo. By use of a nested case-control design within a prospective study, i.e., the Health Professionals Follow-Up Study, we investigated the association between risk of prostate cancer and prediagnostic level of selenium in toenails, a measure of long-term selenium intake. Methods: In 1986, 51529 male health professionals aged 40-75 years responded to a mailed questionnaire to form the prospective study. In 1987, 33737 cohort members provided toenail clippings. In 1988, 1990, 1992, and 1994, follow-up questionnaires were mailed. From 1989 through 1994, 181 new cases of advanced prostate cancer were reported. Case and control subjects were matched by age, smoking status, and month of toenail return. Selenium levels were determined by neutron activation. All $P$ values are twosided. Results: The selenium level in toenails varied substantially among men, with quintile medians ranging from 0.66 to $1.14 \mu \mathrm{g} / \mathrm{g}$ for control subjects. When matched case-control data were analyzed, higher selenium levels were associated with a reduced risk of advanced prostate cancer (odds ratio [OR] for comparison of highest to lowest quintile $=0.49 ; 95 \%$ confidence in-
Selenium is an essential trace nutrient and is critical for the activity of glutathione peroxidase, which may protect DNA and other cellular molecules against oxidative damage (1-3). At relatively high levels, selenium protects against the action of certain carcinogens in various animal models $(4,5)$. In the United States, lower age-specific death rates from some types of cancer have been observed in states with higher soil selenium levels (6). Most studies (7) based on prediagnostic serum selenium levels tend to support an association between low levels of selenium and the risk of various cancers. In a recent double-blind, placebocontrolled cancer prevention trial (8) in which $200 \mu \mathrm{g}$ selenium was given daily to patients with histories of basal and squamous carcinoma, selenium supplementation did not protect against the development of recurrent skin cancers as a primary end point but was inversely associated with the incidence of and mortality from total prostate, lung, and colorectal cancers.

The data are surprisingly sparse regarding a relationship between selenium and prostate cancer, a disease that causes more than 40000 deaths annually in the United States. Combined prospective data based on serum selenium levels from three studies (9-11) sum to a total of only 75 cases of prostate cancer, with the two smallest studies $(9,10)$ suggesting a statistically nonsignificant inverse association. The recent trial by Clark et al. (8), based on a total of 48 cases of prostate cancer, found men who were randomly assigned to receive $200 \mu \mathrm{g}$ selenium daily to be at only one third the risk for prostate cancer $(P=$ .001) compared with those receiving a placebo.

The provocative results from this trial support further study of the relationship between selenium and prostate cancer. This trial indicates that selenium supplementation at doses relatively high compared with the recommended daily allowance for men $(70 \mu \mathrm{g})$ may have an anticancer effect, but few studies address the relation between the selenium acquired from normal dietary intake and the risk of prostate cancer. Toenail selenium levels reflect selenium intake integrated over many months and, thus, are useful indicators of past selenium intake in epidemiologic studies (12-15). We therefore assessed the association between prediagnostic levels of selenium in toenails and subsequent risk of advanced prostate cancer by use of a nested case-control design within the Health Professionals Follow-Up Study $(16,17)$.

\footnotetext{
*Affiliations of authors: K. Yoshizawa, Department of Nutrition, Harvard School of Public Health, Boston. MA; W. C. Willett, M. J. Stampfer, E. B. Rimm, Departments of Nutrition and Epidemiology, Harvard School of Public Health and Channing Laboratory, Department of Medicine, Brigham and Women's Hospital, Harvard Medical School, Boston; S. J. Morris, Research Reactor Center, University of Missouri-Columbia, Research Park; D. Spiegelman, Department of Epidemiology, Harvard School of Public Health; E. Giovannucci, Department of Nutrition, Harvard School of Public Health, and Channing Laboratory, Department of Medicine, Brigham and Women's Hospital, Harvard Medical School.

Correspondence to: Edward Giovannucci, M.D. Sc.D., Channing Laboratory, Department of Medicine, Brigham and Women's Hospital and Harvard Medical School, 181 Longwood Avenue, Boston, MA 02115

See "Notes" following "References."

(C) Oxford University Press
} 


\section{Subjects and Methods}

\section{Population}

The Health Professionals Follow-Up Study is an ongoing prospective cohort study of diet and coronary disease and cancer among 51529 men in the United States from all 50 states who were aged 4075 years in $1986(16,17)$. The study began in 1986 when all cohort members completed a mailed questionnaire that assessed dietary intake, risk factors for cancer and heart disease, and medical history. Among these men, 1595 (3\%) whose reported daily energy intake from the 1986 semiquantitative food frequency questionnaire was less than 800 or greater than $4200 \mathrm{kcal} /$ day or who left 70 or more questions on the questionnaire blank were excluded from the baseline population of 51529 men. Every 2 years, follow-up questionnaires were sent to update information on newly diagnosed prostate cancers. We used the National Death Index to ascertain the status of nonrespondents. In 1987, 33737 sets of toenails were collected from the cohort members and were stored for subsequent analysis. This study was approved by the Human Research Committee at the Harvard School of Public Health.

\section{Case Ascertainment}

On the 1988, 1990, 1992, and 1994 questionnaires, each participant was asked if he had had a diagnosis of prostate cancer during the prior 2-year period. A letter was sent to all men who reported an incident prostate cancer on the follow-up questionnaires to confirm the report and to ask for permission to review medical records. After repeated mailings, we received questionnaires from or had confirmation of deaths for more than $94 \%$ of the eligible participants through 1994.

Prostate cancer was staged by physicians conducting the cohort study according to information received from medical reports. In these analyses, we considered only extraprostatic (advanced) cases of adenocarcinoma of the prostate (stage $\mathrm{C}$ or D). Stage $\mathrm{C}$ cancers are those cancers that have perforated the capsule but remain localized to the periprostatic area; stage D cancers are those that have metastasized to a remote site (17). We included only case subjects diagnosed at least 2 years after collection of the toenail specimen to minimize the potential impact of undiagnosed cancers on selenium levels. All prostate cancers for this analysis were confirmed through a review of histopathologic reports from medical records.

\section{Control Ascertainment}

Each case subject with advanced prostate cancer was matched to a Health Professionals Follow-Up Study participant without a diagnosis of prostate cancer on the basis of age within 1 calendar year, smoking status (current, past [years since smoking was stopped], and never), and date of toenail return within 1 month (the dates of toenail return were matched to reduce differences in levels due to seasonal variation). The control subjects had to be alive and cancer free (other than nonmelanoma skin cancer) at the time that the corresponding case subject was diagnosed with cancer.

\section{Assessment of the Level of Selenium in Toenails}

Before the analysis, the toenail clippings from all toes were washed with deionized water by use of a sonicator. Case and control specimens were analyzed together, but in random order, with the case status unknown to the laboratory personnel. Selenium was analyzed by instrumental neutron activation analysis at the University of Missouri Research Reactor, Columbia, MO (18). ${ }^{77 \mathrm{~m}} \mathrm{Se}$ is produced from ${ }^{76} \mathrm{Se}$ by neutron capture during reactor irradiation. The isomeric transition of ${ }^{77 \mathrm{~m}} \mathrm{Se}$ emits a $161.9-\mathrm{keV}$ photon that is measured by high-resolution gammaray spectroscopy. The selenium concentration is quantified by standard comparison as described $(14,19)$. The coefficient of variation for duplicate selenium neutron activation analysis for nails was less than $2 \%$.

\section{Assessment of Diet and Other Risk Factors}

Nutrient intakes were calculated from the 1986 dietary questionnaire, which included 131 food items with specified portion sizes. The cohort member reported the average frequency at which he had consumed each item during the previous year. The average daily intake of nutrients was calculated by multiplying the frequency of consumption of each food item by the nutrient content, calculated from composition values from U.S. Department of Agriculture sources (20) supplemented with other data from the Harvard University Food Composition Database (November 1993), and summing the nutrient intake from all the food items. Specific brands of multivitamin and selenium supplements were used for the computation of selenium supplement intake (17). The nutrients were adjusted for total energy intake by using the residual method (21).

The food-frequency questionnaire was evaluated in this cohort by use of two 1-week dietary records from a random sample of 127 men living in the Boston area (22). The correlation coefficients, adjusted for total energy intake and week-to-week variation in diet records between the food frequency questionnaire and the average of two 1-week diet records, averaged 0.65 for nutrients (22) and 0.63 for specific foods (23).

On the 1990 questionnaire, participants were asked about a history of prostate cancer in their father and in any brothers. In each follow-up questionnaire, we also inquired whether participants had received a digital rectal examination during the previous 2 years. The history of screening by measurement of prostatic-specific antigen (PSA) was assessed in 1994.

\section{Statistical Analysis}

Because the distribution of toenail selenium levels was skewed toward higher levels, the values were $\log$ transformed to improve normality. The mean and distribution of sample weights did not vary by case-control status, but the Pearson correlation coefficient between the log-transformed selenium level and the sample weight was $-0.34(P<.0001)$. Therefore, to reduce extraneous variation, we adjusted for the toenail sample weight by regression analysis of the log-transformed selenium values on the specimen weight. A constant, the log-transformed pre- dicted selenium level for the mean of the sample weight, was added back to the residuals obtained from the linear regression model, and the values were inverse $\log$ transformed.

Differences in selenium levels between case and control groups were tested by using nonparametric two-sample tests. The association between the selenium level in toenails and the risk of advanced prostate cancer was expressed as an odds ratio (OR), with a $95 \%$ confidence interval (CI). Selenium values were categorized into quintiles based on their distribution among the control subjects. Logistic regression analysis was used to control for known and potential risk factors. We tested for linear trend by using the median value of each quintile of selenium as a continuous variable in a multiple logistic regression model with covariates. All $P$ values reported are two-sided. In addition, we evaluated whether the selenium level was inversely linearly associated with the risk of advanced prostate cancer by using restricted cubic splines (24). Nutrients and body mass index (BMI) were also grouped into quintiles. Smoking status was a matching variable; in multivariate models, we additionally controlled for category of cigarettes per day for current smokers. We tested for an interaction between selenium status and vitamin $\mathrm{E}$ intake because these nutrients may interact as antioxidants (25).

Conditional and unconditional logistic regression gave similar results; therefore, in this report, only the results by the former method were given for the overall analyses. However, we used unconditional logistic regression analysis when we stratified the analyses across levels of vitamin $\mathrm{E}$ intake.

The association between the selenium level in toenails and the geographic distribution of selenium in soil, based on state of residence in 1986, was assessed by using published selenium values $(6,26,27)$. The high-level selenium states had soil selenium levels in the range of greater than or equal to $0.1 \mu \mathrm{g} / \mathrm{g}$ (18 states), medium-level states had soil selenium levels in the range of $0.05-0.09 \mu \mathrm{g} / \mathrm{g}$ (11 states), and low-level states had soil selenium levels between 0.02 and $0.05 \mu \mathrm{g} / \mathrm{g}$ (19 states).

\section{Results}

Table 1 shows the baseline characteristics of control subjects according to selenium levels in toenails. The intake of lycopene, calcium, and saturated fat did not vary appreciably across the levels of selenium in toenails. The percentage of men using supplements that contained selenium (including multivitamins) was lowest among those in the lowest quintile of toenail selenium level. The percentage of men living in states with high soil selenium content was $14 \%$ in the low quintile of toenail selenium and $27 \%$ in the highest quintile of toenail selenium.

Baseline characteristics of the case and control subjects are shown in Table 2. The median ages and proportions of current, never, and past smokers at the baseline in 1986 were the same in the case and control subjects due to the way in which they 
Table 1. Baseline characteristics according to quintile levels of selenium (Se) in toenails ( $\mathrm{n}=181$ control subjects)

\begin{tabular}{|c|c|c|c|c|c|}
\hline \multirow[b]{2}{*}{ Characteristic } & \multicolumn{5}{|c|}{ Median Se level in toenails, ppm* (range) } \\
\hline & $\begin{array}{c}0.66 \\
(0.53-0.73)\end{array}$ & $\begin{array}{c}0.76 \\
(0.73-0.79)\end{array}$ & $\begin{array}{c}0.82 \\
(0.79-0.85)\end{array}$ & $\begin{array}{c}0.88 \\
(0.85-0.94)\end{array}$ & $\begin{array}{c}1.14 \\
(0.94-7.09)\end{array}$ \\
\hline No. of participants & 35 & 37 & 37 & 35 & 37 \\
\hline Median age, y & 64 & 62 & 63 & 65 & 64 \\
\hline Median body mass index, $\mathrm{kg} / \mathrm{m}^{2}$ & 24.3 & 25.6 & 24.4 & 24.7 & 24.4 \\
\hline$\%$ with history of vasectomy & 22.9 & 21.6 & 8.1 & 17.6 & 16.2 \\
\hline$\%$ with prostate cancer family history & 3 & 8 & 3 & 6 & 0 \\
\hline$\%$ with diabetes & 6 & 3 & 5 & 3 & 8 \\
\hline $\begin{array}{l}\text { Smoking status } \\
\% \text { never } \\
\% \text { past, years since quit }\end{array}$ & 37 & 27 & 51 & 57 & 30 \\
\hline $\begin{array}{l}<10 y \\
\geqslant 10 y\end{array}$ & $\begin{array}{r}9 \\
26\end{array}$ & $\begin{array}{l}11 \\
54\end{array}$ & $\begin{array}{l}11 \\
24\end{array}$ & $\begin{array}{r}6 \\
37\end{array}$ & $\begin{array}{l}22 \\
41\end{array}$ \\
\hline $\begin{array}{l}\% \text { current No. of cigarettes per day } \\
1-24 \\
>24 \\
\text { Unknown smoking amount }\end{array}$ & $\begin{array}{r}6 \\
20 \\
3\end{array}$ & $\begin{array}{l}3 \\
5 \\
0\end{array}$ & $\begin{array}{r}11 \\
3 \\
0\end{array}$ & $\begin{array}{l}0 \\
0 \\
0\end{array}$ & $\begin{array}{l}8 \\
0 \\
0\end{array}$ \\
\hline Rectal examination (routine or symptoms), $\%$ & 74 & 73 & 51 & 65 & 68 \\
\hline $\begin{array}{l}\text { Food and nutrients per day } \\
\text { Tomato products, serving } \\
\text { Lycopene, } \mu \mathrm{g} \\
\text { Calcium, mg } \\
\text { Vitamin E, IU† } \\
\text { Saturated fat, g } \\
\% \text { Se from supplement } \ddagger\end{array}$ & $\begin{array}{c}0.6 \\
8008 \\
818 \\
15 \\
21.8 \\
6\end{array}$ & $\begin{array}{c}0.5 \\
6801 \\
915 \\
16 \\
23.8 \\
17\end{array}$ & $\begin{array}{c}0.6 \\
9482 \\
745 \\
12 \\
24.3 \\
19\end{array}$ & $\begin{array}{c}0.6 \\
12044 \\
776 \\
14 \\
21.9 \\
12\end{array}$ & $\begin{array}{c}0.6 \\
8994 \\
826 \\
14 \\
22.6 \\
14\end{array}$ \\
\hline States with Se content in soil, \% in high category & 14 & 27 & 11 & 18 & 27 \\
\hline
\end{tabular}

$* \mathrm{ppm}=$ parts per million $(\mathrm{wt} / \mathrm{wt})$.

$\dagger \mathrm{IU}=$ international units.

†Including multivitamin supplements.

Table 2. Baseline characteristics by disease status*

\begin{tabular}{|c|c|c|}
\hline \multirow[b]{2}{*}{ Characteristic } & \multicolumn{2}{|c|}{ Disease status } \\
\hline & $\begin{array}{l}\text { Control subjects } \\
\quad(\mathrm{n}=181)\end{array}$ & $\begin{array}{c}\text { Case subjects } \\
(\mathrm{n}=181)\end{array}$ \\
\hline Median age, $\mathrm{y}^{\dagger}$ & 63 & 63 \\
\hline Median body mass index, $\mathrm{kg} / \mathrm{m}^{2}$ & 24.6 & 24.6 \\
\hline$\%$ with prostate cancer family history & 4 & 12 \\
\hline$\%$ with diabetes & 5 & 3 \\
\hline $\begin{array}{l}\text { Smoking status } \dagger \\
\% \text { never } \\
\% \text { past } \\
\% \text { current }\end{array}$ & $\begin{array}{l}40 \\
48 \\
12\end{array}$ & $\begin{array}{l}40 \\
48 \\
12\end{array}$ \\
\hline$\%$ rectal examination for routine screening in prior $2 \mathrm{y} \neq$ & 61 & 54 \\
\hline $\begin{array}{l}\text { Food and nutrients per day } \\
\text { Lycopene, } \mu \mathrm{g} \\
\text { Calcium, mg } \\
\text { Vitamin E with supplement, IU§ } \\
\text { Saturated fat, g }\end{array}$ & $\begin{array}{c}9152 \\
818 \\
14.1 \\
23.0\end{array}$ & $\begin{array}{c}8604 \\
853 \\
14.5 \\
24.1\end{array}$ \\
\hline Mean Se level in toenail, $\mu \mathrm{g} / \mathrm{g}$ & 0.96 & 0.82 \\
\hline
\end{tabular}

*Conditional on matched characteristics (age and smoking).

$\dagger$ Matching variable.

$\neq \mathrm{n}=359$.

$\S \mathrm{IU}=$ international units.

were matched. The median BMI in 1986 was the same in the two groups. Reported routine digital rectal examinations were slightly lower on the 1988 questionnaire for the case subjects. The proportion of men with a family history of prostate cancer was higher in the case subjects. A history of diabetes was more common among the control subjects; intake of lycopene was lower among the case subjects, whereas calcium and saturated fat intakes were higher in the case subjects. These associations are similar to those previously reported in the entire cohort $(16,17,28,29)$.

The range of toenail selenium levels among the baseline population (control subjects) was between 0.53 and $7.09 \mu \mathrm{g} / \mathrm{g}$. The mean toenail selenium level was higher in the control subjects $(0.96 \mu \mathrm{g} / \mathrm{g})$ than in the case subjects $(0.82 \mu \mathrm{g} / \mathrm{g})$. This difference was statistically significant (nonparametric paired test, $P=.05$ ).

Table 3 shows the ORs of prostate cancer according to toenail selenium levels. After adjustment for age, smoking, and date when toenail samples were returned by the matching case and control subjects, the OR was 0.49 (95\% CI $=0.25-0.96)$, comparing the highest with the lowest quintiles. The $P$ value for trend using conditional logistic regression analysis on all of the data was .11. After additionally controlling for potential prostate cancer risk factors, including a family history of prostate cancer; BMI; vasectomy; and in- 
Table 3. Odds ratio (OR) for advanced prostate cancer during 7 years of follow-up according to quintile levels of selenium $(\mathrm{Se})(\mathrm{n}=362)$ using conditional logistic regression

\begin{tabular}{|c|c|c|c|c|c|c|}
\hline & \multicolumn{5}{|c|}{ Quintile of Se level } & \multirow{2}{*}{$\begin{array}{l}P \text { for } \\
\text { trend* }\end{array}$} \\
\hline & 1 & 2 & 3 & 4 & 5 & \\
\hline $\begin{array}{l}\text { Se levels in toenail, } \mathrm{ppm} \dagger \\
\text { Median, range }\end{array}$ & $\begin{array}{c}0.66 \\
(0.53-0.73)\end{array}$ & $\begin{array}{c}0.76 \\
(0.73-0.79)\end{array}$ & $\begin{array}{c}0.82 \\
(0.79-0.85)\end{array}$ & $\begin{array}{c}0.88 \\
(0.85-0.94)\end{array}$ & $\begin{array}{c}1.14 \\
(0.94-7.09)\end{array}$ & \\
\hline Case subjects $(\mathrm{n}=181)$ & 54 & 34 & 29 & 36 & 28 & \\
\hline Control subjects $(\mathrm{n}=181)$ & 35 & 37 & 37 & 35 & 37 & \\
\hline $\begin{array}{l}\text { OR } \ddagger \\
(95 \% \mathrm{CI}) \S\end{array}$ & 1.00 & $\begin{array}{c}0.57 \\
(0.29-1.12)\end{array}$ & $\begin{array}{c}0.53 \\
(0.28-1.01)\end{array}$ & $\begin{array}{c}0.67 \\
(0.34-1.32)\end{array}$ & $\begin{array}{c}0.49 \\
(0.25-0.96)\end{array}$ & .11 \\
\hline $\begin{array}{l}\text { Multivariate OR\| } \\
(95 \% \mathrm{CI})\end{array}$ & 1.00 & $\begin{array}{c}0.62 \\
(0.29-1.35)\end{array}$ & $\begin{array}{c}0.35 \\
(0.16-0.78)\end{array}$ & $\begin{array}{c}0.80 \\
(0.35-1.80)\end{array}$ & $\begin{array}{c}0.39 \\
(0.18-0.84)\end{array}$ & .05 \\
\hline $\begin{array}{l}\text { Multivariate ORII } \\
(95 \% \text { CI })\end{array}$ & 1.00 & $\begin{array}{c}0.59 \\
(0.27-1.30)\end{array}$ & $\begin{array}{c}0.35 \\
(0.16-0.78)\end{array}$ & $\begin{array}{c}0.76 \\
(0.34-1.73)\end{array}$ & $\begin{array}{c}0.35 \\
(0.16-0.78)\end{array}$ & .03 \\
\hline
\end{tabular}

*Two-sided $P$ for trend across quintiles.

$\dagger$ ppm $=$ parts per million $(\mathrm{wt} / \mathrm{wt})$.

\$Case and control subjects matched for age, smoking, and date of return of toenails. OR = odds ratio. $\S \mathrm{CI}=$ confidence interval.

|Adjusted for quintiles of lycopene, saturated fat, and calcium, for family history of prostate cancer (binary), for body mass index (quintiles), and for vasectomy (binary).

q[Further adjusted for region (soil selenium content high, medium, and low); $\mathrm{n}=354$; four pairs with missing information were excluded.

takes of lycopene, calcium, and saturated fat, the OR was $0.39(95 \% \mathrm{CI}=0.18$ $0.84)$; when all of the data were used, the $P$ value for trend was .04. Additional adjustment for region (high, medium, and low levels of soil selenium content) did not change the risk appreciably. The cubic spline analysis indicated that the log incidence rate of advanced prostate cancer risk decreased throughout the entire range of selenium levels.

We examined the relationship between the selenium level in toenails and the risk of advanced prostate cancer across strata of vitamin $\mathrm{E}$ intake by use of unconditional logistic regression analysis. Among men $(n=233)$ with daily intakes of vitamin $\mathrm{E}$ less than or equal to $30 \mathrm{IU}$, the ORs across quintiles $1-5$ were 1.0 (reference), 0.63 (95\% CI $=0.26-1.53$ ), 0.41 (95\% CI $=0.16-1.07), 0.75(95 \% \mathrm{CI}=$ $0.30-1.89$ ), and 0.29 (95\% CI $=0.11-$ 0.77 ), respectively; the $P$ value for trend was .025. Among 125 men who obtained substantial amounts of vitamin $\mathrm{E}$ from supplements (>30 IU/day), those in the lowest quintile of selenium were at highest risk, but there was no trend $(P=.68)$ across quintiles $2-5$ (ORs across quintiles $1-5$ were 1.0 [reference], 0.29 [95\% CI = 0.07-1.18], 0.27 [95\% CI $=0.06-1.17$, $0.32[95 \% \mathrm{CI}=0.07-1.53]$, and 0.41 [95\% CI $=0.09-1.83]$, respectively). We tested for multiplicative interaction between selenium level and intake of vita- min $\mathrm{E}$ by including a variable for the product of selenium level and vitamin $\mathrm{E}$ in a logistic regression model, along with selenium and vitamin $\mathrm{E}$ individually, and testing for significance of this interaction term. No interaction between selenium and vitamin $\mathrm{E}$ was evident $(P=.30)$.

We evaluated potential modification of the selenium effect by the level of smoking, which is known to reduce selenium levels (14). The inverse association between selenium and prostate cancer did not differ by smoking status ( $P$ value for multiplicative interaction $>.5)$. When current smokers were excluded, the multivariate OR did not change appreciably (between high and low quintiles OR = $0.42 ; 95 \% \mathrm{CI}=0.20-0.91 ; P$ for trend $=$ .03). Also, exclusion of current smokers or men who had quit within the past 5 years yielded similar results $(\mathrm{OR}=0.44$; $95 \% \mathrm{CI}=0.20-0.97$, controlling for the number of cigarettes among those who smoked more than 5 years in the past; $P$ for trend $=.05$ ).

\section{Discussion}

We found a strong inverse association between the prediagnostic selenium level assessed in toenail clippings and the risk of advanced prostate cancer. This inverse association was not a result of any confounding effect of various factors, including age, other dietary factors, smoking,
BMI, geographic region, family history of prostate cancer, or vasectomy. Although the technologies for diagnosing prostate cancer changed during the course of the study, the probability of being diagnosed conditional on cancer was likely to be independent of selenium level, and the vast majority of advanced prostate cancers would be clinically diagnosed in this population. Moreover, the percent of men who had reported a recent negative digital rectal examination at baseline did not differ substantially across levels of selenium. Over the course of the study, screening by PSA measurement became widely used, and rates of PSA testing were similar by level of baseline selenium (across quintiles $1-5$, respectively, $96 \%, 84 \%, 93 \%$, $85 \%$, and $84 \%$ of the control subjects had had a PSA test by 1994).

We minimized the possibility that undiagnosed cancers artifactually lowered selenium levels by excluding the first 2 years of follow-up. Also, the selenium level in 1987 was identical in case subjects diagnosed across the follow-up period $(0.82 \mu \mathrm{g} / \mathrm{g}$ for cases of cancer diagnosed in the 2-year periods from 1989 through 1990, from 1991 through 1992, and from 1993 through 1994); if undiagnosed cancers had reduced selenium levels, the levels in case subjects should have been lower in the early years of followup. The mean selenium level was the same $(0.82 \mu \mathrm{g} / \mathrm{g})$ for case subjects who had reported a recent digital rectal examination at baseline and those who had not. Because smoking can lower selenium levels, we matched subjects for cigarette use to exclude this as a confounder and found that the inverse association between the selenium level in toenails and the risk of prostate cancer persisted among never smokers and past smokers who had not smoked for at least 5 years.

In this study, the association between selenium level and the risk of prostate cancer at stages A and B was not evaluated. On the basis of our results, selenium could plausibly either influence early stages of prostate carcinogenesis, ultimately leading to a decrease in overall prostate cancer incidence, or affect the progression from organ confined to extraprostatic disease. Alternately, cancers at stage A or B may be inherently different from cancers at stage $\mathrm{C}$ or $\mathrm{D}$. In either case, the advanced stage cases are most 
important clinically because these lead to symptoms and death, and they are less prone to detection bias.

Toenail clippings provide useful measures of long-term average intake of selenium. Longnecker et al. (13) showed that toenail selenium levels reflect intake integrated over 26-52 weeks, and the Pearson correlations with selenium intake were .78 for whole blood and .67 for toenails. Furthermore, toenail selenium levels indicate long-term status; among women in the Nurses' Health Study, the Spearman correlation was .48 for specimens obtained 6 years apart from the same person (15). Single measures of various parameters (e.g., blood pressure, cholesterol, or glucose), which have similar correlations over time, are strong predictors of disease. If misclassification is random and nondifferential by casecontrol status, the magnitude of any true association would tend to be underestimated.

The level of selenium in toenails reflects intake from dietary and supplementary sources. The selenium content of foods is largely dependent on the selenium content of the soil where the food or animal feed was grown. In our study, the regional selenium content of soil and the use of selenium supplements predicted selenium levels in toenail clippings, albeit moderately, supporting the use of toenails as an indicator of selenium intake. Other unmeasurable sources of variation, such as dietary pattern and absorption and excretion, contribute to produce a wide range in levels, from a median of 0.66 parts per million (wt/wt) in the bottom quintile to 1.14 parts per million (wt/wt) in the top quintile. The difference in these levels is substantial and is comparable to the range found in a sample of people living in the Boston area $(0.74 \mu \mathrm{g} / \mathrm{g})$, a region with a relatively low soil selenium content, and another sample of people living in South Dakota $(1.17 \mu \mathrm{g} / \mathrm{g})$, an area with a very high soil selenium level (30). With the use of formulas derived from direct measurements of selenium in the diet based on multiple, 1-day, duplicate-plate food composites and from toenail specimens, the estimated daily median selenium intake was found to be $86 \mu \mathrm{g}$ among men in the low quintile of selenium level in toenails and $159 \mu \mathrm{g}$ among the men in the high quintile (13). These should be considered rough estimates because of differ- ences, such as in the chemical form of selenium, in the diet of our population and that from which the formulas were derived (South Dakota and Wyoming).

Prospective data on the relationship between selenium status and prostate cancer are sparse. Two small studies of 11 (9) and 13 (10) case subjects found nonsignificant inverse associations between the level of selenium in plasma and the risk of prostate cancer, but a larger study of 51 case subjects did not (11). However, in a recent randomized selenium supplementation trial (8) conducted in areas with low soil selenium content, men who received $200 \mu \mathrm{g}$ of selenium daily had a relative risk of $0.35(95 \% \mathrm{CI}=0.18$ $0.65)$ for prostate cancer compared with those who received a placebo $(P=.001)$. These results, based on 48 cases of prostate cancer, were remarkably similar to our relative risk based on a comparison of high and low quintiles of toenail selenium levels. In the trial, the reduction in risk among those randomly assigned to receive selenium was observed for individuals with cancers at stage $\mathrm{A}$ or $\mathrm{B}$ as well as for individuals with cancers at more advanced stages (31).

The results from the trial alone do not allow us to distinguish whether a benefit occurs only at relatively high supplemental doses or whether a relationship within normal dietary ranges exists; the men received $200 \mu \mathrm{g}$ daily in addition to their normal dietary intake (the recommended daily allowance for men is $70 \mu \mathrm{g}$ ). Because supplementary intake in our population was low, our results suggest that the recommended and actual dietary intakes of selenium may be suboptimal for many men in the United States with regard to prostate cancer risk. Our analyses indicated an inverse association that was linear throughout the entire range of selenium levels.

Vitamin $\mathrm{E}$ is known to interact with selenium in preventing the formation of oxidative products of polyunsaturated fatty acids, some of which may be carcinogenic (25). Also, the Alpha-Tocopherol, Beta-Carotene Trial indicated a benefit of $\alpha$-tocopherol on prostate cancer (32). The inverse association between selenium intake and advanced prostate cancer risk was slightly stronger after excluding men with an intake of vitamin $E$ that exceeded $30 \mathrm{IU} /$ day that was mostly from supplementary sources $(\mathrm{OR}=0.29)$. The interaction between selenium and vitamin E was not statistically significant, but our sample size to test for interaction was limited.

The biologic mechanism whereby selenium affects prostate cancer is unknown, but several mechanisms have been hypothesized. Selenium was suggested as an anticarcinogenic agent by Griffin (33) because of its role as an essential component of selenium-dependent glutathione peroxidase. This hypothesis is supported by the mutagenicity and carcinogenicity of malonyldialdehyde, which is thought to be formed with selenium deficiency. Regulation of apoptosis appears to be an important determinant of cancer risk, and antitumorigenic activities of selenium compounds have been related to apoptotic responses $(34,35)$.

In conclusion, the findings of our study provide further support for the hypothesis that a higher intake of selenium may reduce the risk of advanced prostate cancer. Our results support further prospective studies and randomized trials of this relationship to confirm or to refute the findings and to determine optimum dose levels.

\section{References}

(1) Chow CK. Nutritional influence on cellular antioxidant defense systems. Am J Clin Nutr 1979;32:1066-81.

(2) Combs GF Jr, Combs SB. The nutritional biochemistry of selenium. Annu Rev Nutr 1984; 4:257-80.

(3) Combs GF Jr, Clark LC. Can dietary selenium modify cancer risk? Nutr Rev 1985;43:325-31.

(4) Halliwell B, Gutteridge JM. Free radicals in biology and medicine. New York: Oxford University Press; 1989.

(5) Griffin AC. The chemoprevention role of selenium carcinogenesis. In: Arnott MS, van Eys J, Wang YM, editors. Molecular interrelations of nutrition and cancer. New York: Raven Press; 1982. p. 401-8.

(6) Shamberger RJ, Tytko SA, Willis CE. Antioxidants and cancer. Part VI. Selenium and ageadjusted human cancer mortality. Arch Environ Health 1976;31:231-5.

(7) Comstock GW, Bush TL, Helzlsouer K. Serum retinol, beta-carotene, vitamin $\mathrm{E}$, and selenium as related to subsequent cancer of specific sites. Am J Epidemiol 1992;135:115-21.

(8) Clark LC, Combs GF, Jr., Turnbull BW, Slate EH, Chalker DK, Chow J, et al. Effects of selenium supplementation for cancer prevention in patients with carcinoma of the skin. A randomized controlled trial. Nutritional Prevention of Cancer Study Group [published erratum appears in JAMA 1997;277:1520]. JAMA 1996;276:1957-63.

(9) Willett WC, Polk BF, Morris JS, Stampfer MJ, 
Pressel S, Rosner B, et al. Prediagnostic serum selenium and risk of cancer. Lancet 1983;2: $130-4$.

(10) Coates RJ, Weiss NS, Daling JR, Morris JS, Labbe RF. Serum levels of selenium and retinol and the subsequent risk of cancer. Am J Epidemiol 1988;128:515-23.

(11) Knekt P, Aromaa A, Maatela J, Alfthan G, Aaran RK, Hakema M, et al. Serum selenium and subsequent risk of cancer among Finnish men and women. J Natl Cancer Inst 1990;82: 864-8.

(12) Willett W. Nutritional epidemiology: issues and challenges. Int J Epidemiol 1987;16: 312-7.

(13) Longnecker MP, Stram DO, Taylor PR, Levander OA, Howe M, Veillon $\mathrm{C}$, et al. Use of selenium concentration in whole blood, serum, toenails, or urine as a surrogate measure of selenium intake. Epidemiology 1996;7:384-90.

(14) Hunter DJ, Morris JS, Chute CG, Kushner E, Colditz GA, Stampfer MJ, et al. Predictors of selenium concentration in human toenails. Am J Epidemiol 1990;132:114-22.

(15) Garland M, Morris JS, Rosner BA, Stampfer MJ, Spate VL, Baskett CJ, et al. Toenail trace element levels as biomarkers: reproducibility over a 6-year period [published erratum appears in Cancer Epidemiol Biomarkers Prev 1994;3:523]. Cancer Epidemiol Biomarkers Prev 1993;2:493-7.

(16) Giovannucci E, Rimm EB, Colditz GA, Stampfer MJ, Ascherio A, Chute CC, et al. A prospective study of dietary fat and risk of prostate cancer. J Natl Cancer Inst 1993;85: 1571-9.

(17) Giovannucci E, Ascherio A, Rimm EB, Stampfer MJ, Colditz GA, Willett WC. Intake of carotenoids and retinol in relation to risk of prostate cancer. J Natl Cancer Inst 1995;87: 1767-76.

(18) Cheng TP, Morris JS, Koirtyohann SR, Spate VL, Baskett CK. The analysis of human nails for 24 elements via $k_{0}$ and cyclic neutron activation analysis. Nuclear Instru Methods Physics Res A 1994;353:457-60.
(19) McKown DM, Morris JS. Rapid measurement of selenium in biological samples using instrumental neutron activation analysis. J Radioanal Chem 1978;43:411-20.

(20) U. S. Department of Agriculture. Composition of foods-raw, processed, and prepared, 1989 Supplement. In: Agricultural Handbook No. 8 Series. Washington (DC): Department of Agriculture, Government Printing Office; 1990.

(21) Willett W. Nutritional epidemiology. In: MacMahon B, editor. Monographs in epidemiology and biostatistics. Vol 15. New York: Oxford University Press; 1990.

(22) Rimm EB, Giovannucci EL, Stampfer MJ, Colditz GA, Litin LB, Willett WC. Reproducibility and validity of a expanded self-administered semiquantitative food frequency questionnaire among male health professionals. Am J Epidemiol 1992;135: 1114-26.

(23) Feskanich D, Rimm EB, Giovannucci EL, Colditz GA, Stampfer MJ, Litin LB, et al. Reproducibility and validity of food intake measurements from a semiquantitative food frequency questionnaire. J Am Diet Assoc 1993; 93:790-6.

(24) Durrleman S, Simon R. Flexible regression models with cubic splines. Stat Med 1989;8: 551-61.

(25) Packer L. Protective role of vitamin E in biological systems. Am J Clin Nutr 1991;53(4 Suppl):1050S-55S.

(26) Kubota J, Allaway WH. Geographic distribution of trace elements problems. In: Micronutrients in agriculture. Madison, (WI): Soil Science Society of America; 1972.

(27) Kubota J, Allaway WH, Carter DL, Cary EE, Lazar VA, et al. Selenium in crops in the United States in relation to seleniumresponsive diseases of animals. J Agric Food Chem 1967;15:448-53.

(28) Giovannucci E, Rimm EB, Wolk A, Ascherio A, Stampfer MJ, Colditz GA, et al. Calcium and fructose intake in relation to risk of prostate cancer. Cancer Res 1998;58:442-7.
(29) Giovannucci E, Rimm E, Stampfer M, Colditz GA, Willett WC. Diabetes mellitus and risk of prostate cancer (United States). Cancer Causes Control 1998;9:3-9.

(30) Morris JS, Stampfer MJ, Willett W. Dietary selenium in humans: Toenails as an indicator. Biol Trace Elem Res 1983;5:529-37.

(31) Clark LC, Dalkin B, Krongrad A, Combs GF Jr., Turnbull BW, Slate EH, et al. Decreased incidence of prostate cancer with selenium supplementation: results of a double-blind cancer prevention trial. Br J Urol 1998;81: $730-4$.

(32) The effect of vitamin E and beta carotene on the incidence of lung cancer and other cancers in male smokers. The AlphaTocopherol, Beta-Carotene Cancer Prevention Study Group. N Engl J Med 1994;330: 1029-35.

(33) Griffin AC. Role of selenium in the chemoprevention of cancer. Adv Cancer Res 1979;29: 419-42.

(34) el-Bayoumy K, Chae YH, Upadhyaya P, Meschter C, Cohen LA, Reddy BS. Inhibition of 7,12dimethylbenz $(a)$ anthracene-induced tumors and DNA adduct formation in the mammary glands of female Sprague-Dawley rats by the synthetic organoselenium compound, 1,4phenylenebis(methylene)selenocyanate. Cancer Res 1992;52:2402-7.

(35) Thompson HJ, Wilson A, Lu J, Singh M, Jiang C, Upadhyaya $\mathrm{P}$, et al. Comparison of the effects of an organic and an inorganic form of selenium on a mammary carcinoma cell line. Carcinogenesis 1994;15:183-6.

\section{Notes}

Supported by Public Health Service grants CA55075 (National Cancer Institute) and HL35464 (National Heart, Lung, and Blood Institute), National Institutes of Health, Department of Health and Human Services.

Manuscript received January 4, 1998; revised June 10, 1998; accepted June 17, 1998. 
Modification of Clinical

Presentation of Prostate

Tumors by a Novel Genetic
Variant in CYP3A4

Timothy R. Rebbeck, Julie M.

Jaffe, Amy H. Walker, Alan J.

Wein, S. Bruce Malkowicz*

Background: Pathways involved in androgen metabolism have been implicated in the etiology of prostate cancer. The goal of this study was to evaluate the effect of CYP3A4, a gene associated with the oxidative deactivation of testosterone, on the clinical presentation of prostate cancers. Methods: A polymerase chain reaction-based approach was used to identify sequence variants of the human CYP3A4 gene. To ascertain whether allelic variants of the CYP3A4 gene were associated with tumor stage and grade and age of the patient at diagnosis, we determined CYP3A4 genotypes in 230 Caucasian men with incident prostate cancer. $R e$ sults: We identified a novel genetic variant (CYP3A4-V) that has an altered $5^{\prime}$ regulatory element, containing an $A$ to $G$ mutation, upstream of the CYP3A4 gene. We then compared clinical characteristics of prostate cancers in men who did and did not carry this variant. The presence of the CYP3A4-V allele was associated with a higher tumor-lymph node-metastasis (TNM) stage and Gleason grade. The association between CYP3A4 genotype and tumor stage was most pronounced in men diagnosed at a relatively old age who reported no family history of prostate cancer. In this group, $46 \%$ of men with stage T3/T4 tumors carried CYP3A4-V, whereas only $5 \%$ of individuals with stage $\mathrm{T} 1$ tumors carried CYP3A4-V (adjusted odds ratio $=9.45$; 95\% confidence interval $=2.54-35.17$; $\chi_{1}^{2}=12.28$; two-sided $P<.001$ ). Conclusions: We determined that a single base change in the $5^{\prime}$ flanking region of the CYP3A4 gene was associated with higher clinical stage and grade in men with prostate tumors. Our results suggest that mutations in the CYP3A4 gene may influence prostate carcinogenesis. [J Natl Cancer Inst 1998;90: 1225-9]

The etiology of prostate cancer involves the effects of androgens as well as of inherited genotypes that may regulate androgen metabolism. Candidate prostate cancer genes include those involved in androgen metabolism, such as the androgen receptor $(1,2)$ or $5 \alpha$-reductase type II (3) genes. Additional candidates include members of the cytochrome P450 supergene family involved in androgen metabolism. One member of this multigene family is CYP3A4, a gene involved in the oxidation of testosterone to $2 \beta-, 6 \beta-$, or $15 \beta$-hydroxytestosterone (4). Substantial interindividual variability in metabolism of specific compounds by the Cyp3a4 protein has been reported (5), yet no genetic basis for this variability has been found. It has also been reported that the Cyp3a4 protein is expressed in only $61 \%$ of prostate tumors (6), which suggests that there is tumor-specific variability in Cy3a4 protein expression.

The goal of this study was to identify germline genetic variants in the CYP3A4 gene that may be used as molecular biomarkers in studies of prostate cancer susceptibility. We searched for variants in the CYP3A4 gene and identified a previously unreported variant in a regulatory element in the $5^{\prime}$ regulatory region of the CYP3A4 gene. We then examined the relationship between variant CYP3A4 genotypes and the clinical presentation of prostate cancer.

\section{Subjects and Methods}

\section{Sample Subjects and Biosample Collection}

A reference panel $(n=94)$ consisting of healthy, unrelated, Caucasian, male volunteers with no history of cancer at any site was assembled at the Hospital of the University of Pennsylvania, Philadelphia, and was used to identify variants in CYP3A4. The mean age of these men was 63.4 years (standard deviation $[\mathrm{SD}]=12.3$ years; range $=23-89$ years). A sample of 230 patients representing incident prostate cancer case subjects was identified through the Urologic Oncology Clinics at the Hospital of the University of Pennsylvania during the period from July 1994 through November 1997. Because of small numbers in other ethnic groups, only nonHispanic, Caucasian men were included in this study. Men were excluded from this study if they had any history of exposure to finasteride at the time of their prostate cancer diagnosis. Patients who were nonincident case subjects (i.e., those diagnosed $>12$ months before the date of study ascertainment) were also excluded. The mean age at diagnosis was 63.3 years $(\mathrm{SD}=7.8$ years; range $=45-90$ years). Written, informed consent was obtained from all participants in the context of a study protocol (\#3614-2) approved by the Committee on Studies Involving Human Beings at the University of Pennsylvania.

Genomic DNA for this study was collected by each study subject using sterile cheek swabs (CytoPak Cytosoft Brush; Medical Packaging Corporation, Camarillo, CA). We processed the genomic DNA by using a protocol modified from that of Richards et al. (7). Briefly, the swab brush was placed inside a 1.5-mL microcentrifuge tube, and $600 \mu \mathrm{L}$ of $50 \mathrm{mM} \mathrm{NaOH}$ was added. The closed tube was vortexed for 5 minutes and then heated at $95^{\circ} \mathrm{C}$ for 10 minutes. Finally, $120 \mu \mathrm{L}$ of $1 M$ Tris (pH 8.0) was added, after which the brush was removed and discarded.

Information on clinical characteristics of the patients at diagnosis was abstracted from medical records. These characteristics included clinical and pathologic Gleason grade (8), prostate-specific antigen (PSA) levels at diagnosis, and TNM (tumorlymph node-metastasis) (9) stage. One hundred forty-five $(63 \%)$ subjects underwent radical prostatectomy for treatment of their disease. In these patients, tumor stage and grade were determined by histopathologic review, which described the capsular status, percent tumor volume, and seminal vesicle involvement. Tumors from the remaining 85 patients were staged by a combination of measurement of serum PSA levels, digital rectal examination, bone scan, and endorectal magnetic resonance imaging. Of the 13 patients diagnosed with T3c stage tumors, eight of these diagnoses were based only on PSA levels, digital rectal examination, magnetic resonance imaging, and bone scan alone, while five patients also underwent seminal vesicle biopsy. Pathologic grading with the use of the Gleason system was undertaken after six to 11 transrectal ultrasound-guided needle biopsies. The Hospital of the University of Pennsylvania investigators reinterpreted the diagnoses of the original biopsy material made at other institutions. For analysis, three TNMstage variables were considered. First, we considered stages T1a-T1c (denoted T1), T2a-T2c (denoted T2), and T3/T4. Second, we considered a binary stage variable of nonpalpable (stages T1aT1c) and palpable (stages T2a-c, T3a-c, and T4a-b) disease. Finally, we considered a combined disease classification defined simultaneously by stage and grade, in which tumors of stages $\mathrm{T} 1 \mathrm{a}-\mathrm{c}$ and of a

*Affiliations of authors: T. R. Rebbeck, J. M Jaffe, A. H. Walker (Department of Biostatistics and Epidemiology), A. J. Wein, S. B. Malkowicz (Department of Urology), University of Pennsylvania School of Medicine, Philadelphia.

Correspondence to: Timothy R. Rebbeck, Ph.D., Department of Biostatistics and Epidemiology, University of Pennsylvania School of Medicine, 904 Blockley Hall, 423 Guardian Dr., Philadelphia, PA 19104-6021 (e-mail: rebbeck@cceb.med.upenn. edu).

See "Notes", following "References."

(C) Oxford University Press 
Gleason grade less than 7 were compared with tumors of stages T2-T4 or T1 and of a Gleason grade greater than or equal to 7. Additional risk factor information was obtained from the subjects by selfreport using a questionnaire. These variables included demographic characteristics, medical history, and family history of prostate cancer.

\section{CYP3A4 Genotype Analysis}

Variant alleles were detected by polymerase chain reaction (PCR) amplification of a 592-base-pair (bp) fragment upstream from the coding region of the CYP3A4 gene that included a portion of exon 1 (nucleotides -571 to +22 ). The primers used in this amplification (5'-AAC AGG GGT GGA AAC ACA AT- $3^{\prime}$ and 5'-CTT TCC TGC CCT GCA CAG-3') were generated from the CYP3A4-specific nucleotide sequence published by Hashimoto et al. (10). The PCR reaction mixture consisted of $10 \mu \mathrm{L}$ of double-distilled $\mathrm{H}_{2} \mathrm{O}, 5 \mu \mathrm{L}$ of $10 \times$ PCR buffer (The Perkin-Elmer Corp., Foster City, CA), $3 \mu \mathrm{L}$ of 25 $\mathrm{m} M \mathrm{Mg}^{2+}, 1 \mu \mathrm{L}$ each of $10 \mathrm{~m} M$ deoxynucleoside triphosphates, $5 \mu \mathrm{L}$ each of $5 \mathrm{~m} M$ PCR primers, 10 $\mu \mathrm{L}$ of template DNA, $0.8 \mu \mathrm{L}$ of Taq polymerase (Amplitaq; The Perkin-Elmer Corp.), and $12.2 \mu \mathrm{L}$ of double-distilled $\mathrm{H}_{2} \mathrm{O}$, for a total volume of $50 \mu \mathrm{L}$. The temperature profile for the PCR reaction was one cycle each at $94^{\circ} \mathrm{C}$ for 5 minutes and $82^{\circ} \mathrm{C}$ for 1 minute, followed by 25 cycles of $94^{\circ} \mathrm{C}$ for 1 minute, $66^{\circ} \mathrm{C}$ for 1 minute with a $0.5^{\circ} \mathrm{C}$ per cycle decrease, and $72{ }^{\circ} \mathrm{C}$ for 1 minute. This procedure was followed by eight cycles at $94{ }^{\circ} \mathrm{C}$ for 1 minute, $50{ }^{\circ} \mathrm{C}$ for 1 minute, and $72{ }^{\circ} \mathrm{C}$ for 1 minute and a final single 10 -minute cycle at $72^{\circ} \mathrm{C}$.

Genotypes were visualized by conformationsensitive gel electrophoresis (CSGE) of the PCR product on a $10 \%$ nondenaturing polyacrylamide gel by use of the protocol of Ganguly et al. (11), after staining was done with ethidium bromide. For the identification of homozygous wild-type (W/W), homozygous variant $(\mathrm{V} / \mathrm{V})$, and heterozygous $(\mathrm{W} / \mathrm{V})$ genotypes with the use of CSGE, two samples were loaded onto the polyacrylamide gel for each subject (Fig. 1). In one well, a 6- $\mu$ L PCR sample was loaded with $6 \mu \mathrm{L}$ of PCR-generated homozygous variant (V/V) DNA from a known V/V subject (denoted " $+\mathrm{V} / \mathrm{V}$ " in Fig. 1). In a second well, a $12-\mu \mathrm{L}$ PCR sample was loaded onto the gel without the addition of V/V DNA (denoted "-V/V" in Fig. 1). In V/V subjects, a single (homoduplex) band was always observed. In W/V subjects, homoduplex and heteroduplex bands were always observed. Thus, the addition of V/V DNA had no effect on the banding pattern for $\mathrm{V} / \mathrm{V}$ and $\mathrm{W} / \mathrm{V}$ subjects. In W/W subjects, a single (homoduplex) band was present in those lanes without V/V DNA. The addition of known V/V DNA to the DNA of subjects with W/W genotypes produced both homoduplex and heteroduplex bands.

\section{Statistical Analyses}

Nonparametric methods were used to compare proportions in contingency tables using two-sided Fisher's exact tests (FETs) and/or Kruskal-Wallis $\chi^{2}$ statistics (for analysis of continuous variables such as PSA level or Gleason grade). Odds ratios were estimated by use of logistic regression models for polytomous or binary outcome stage or grade data. All odds ratio estimates were adjusted for pa-

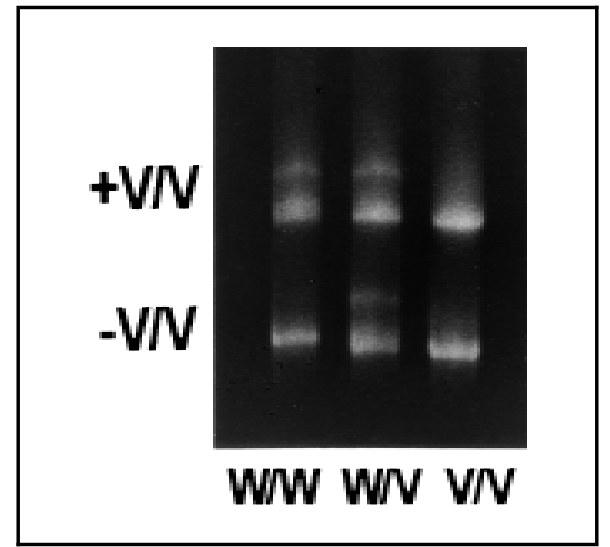

Fig. 1. Analysis of the nifedipine-specific element variant at CYP3A4 by conformation-sensitive gel electrophoresis (CSGE). The appearance of homozygous variants $(\mathrm{V} / \mathrm{V})$ and heterozygotes $(\mathrm{W} / \mathrm{V})$ is identical in the presence $(+)$ and absence $(-)$ of homozygous variant (V/V) DNA. The addition of V/V DNA to homozygous W/W samples induces the generation of heteroduplexes in CSGE analysis and results in the presence of an additional band.

tient's age at diagnosis and method of prostate cancer detection. The detection method was coded as three binary (yes/no) covariates describing referral for diagnosis because of elevated PSA levels, abnormal results from digital rectal examination at routine screening, and/or the existence of prostate cancer symptoms. Stratified analyses were undertaken to compare genotype effects by family history of prostate cancer and age of the patient at diagnosis. Positive family history of prostate cancer was defined as having at least one first- or second-degree relative with prostate cancer. With the use of this definition, $25 \%$ of patients had a positive family history. Therefore, an individual in this study defined as having a positive family history of prostate cancer did not necessarily come from a family with a hereditary pattern of prostate cancer. Age at diagnosis was stratified at the median age of diagnosis (63 years) for the study population to distinguish "earlier age at diagnosis", patients (i.e., those diagnosed at or before 63 years of age) from "later age at diagnosis" patients (i.e., those diagnosed after 63 years of age). The Cochran-Mantel-Haenszel chi-squared test $\left(\chi_{\mathrm{CMH}}^{2}\right)$ for nonzero correlation among strata was used to compare contingency tables stratified by family history of prostate cancer and/or age at diagnosis.

\section{Results}

\section{Variant Genotype Identification}

With the use of a reference sample of 94 unselected, unrelated Caucasians with no history of cancer at any site, 15 carriers of variant alleles (12 heterozygotes and three homozygotes) were identified by CSGE analysis of the $5^{\prime}$ regulatory region of the CYP3A4 gene. These subjects were confirmed by direct sequencing to carry an $A$ to $G$ transition mutation that alters the 10-bp (AGGGCAAGAG to AGGG-
CAGGAG) nifedipine-specific element (NFSE), located -287 to $-296 \mathrm{bp}$ from the transcription start site of the CYP3A4 gene (10). Sequence analysis was also undertaken on a randomly selected set of 12 of the 79 individuals inferred to be homozygous wild-type from CSGE. No nucleotide changes relative to the wild-type sequence were detected in these individuals. Thus, we estimated the CYP3A4 variant allele frequency in the U.S. Caucasian population to be $9.6 \%$ (18 variant alleles among 188 chromosomal copies), with an observed heterozygosity of $12.8 \%$. The NFSE is a purine-rich element that has homology with the basic transcription element. The NFSE has been previously identified as a CYP3A4-specific element that is bound by nuclear proteins and falls within a region required for CYP3A4 gene transcription in HepG2 cells (a human hepatoma cell line) (10).

\section{Association of CYP3A4 Genotypes With Prostate Cancer}

Analyses were undertaken to evaluate the relationship between CYP3A4 genotypes and clinical characteristics of prostate tumors. We found no association between CYP3A4 genotype and the PSA level at diagnosis in analysis of unadjusted PSA $\left(\chi^{2}=0.22 ; P=.637\right)$ or PSA adjusted for age and mode of prostate cancer detection $\left(\chi^{2}{ }_{1}=2.14 ; P=\right.$ .143). We also found no significant association between genotype and PSA level in any group defined by age at diagnosis or family history of prostate cancer. Genotype was not associated with an earlier age at diagnosis in unadjusted analysis $\left(\chi_{1}^{2}=1.12 ; P=.290\right)$ or in analysis adjusted for method of prostate cancer detection $\left(\chi_{1}^{2}=0.71 ; P=.399\right)$.

CYP3A4-V genotypes were overrepresented in tumors of higher stage and grade (Tables 1 and 2). As shown in Table 1,

CYP3A4-V genotypes were more common in tumors of higher stage $(P=.081$ $\left.[\mathrm{FET}] ; \chi^{2}{ }_{1}=5.12 ; P=.024\right)$, and there were significant differences in this relationship by family history of prostate cancer and age at diagnosis $\left(\chi_{\mathrm{CMH}}^{2}=4.91\right.$; $d f=1 ; P=.027)$. We observed no association between the CYP3A4 genotype and stage in men with a family history of prostate cancer or whose tumor was diagnosed at an earlier age, possibly as a result of small sample sizes. However, there was a significant effect of genotype in pa- 
Table 1. Association of CYP3A4 genotype with TNM stage in 230 incident prostate cancer patients

\begin{tabular}{|c|c|c|c|c|c|c|}
\hline \multirow[b]{2}{*}{ Stage* } & \multicolumn{2}{|c|}{ No family history of prostate cancer $\dagger$} & \multicolumn{2}{|c|}{ Positive family history of prostate cancer $\dagger$} & \multicolumn{2}{|c|}{$\begin{array}{l}\text { All individuals without regard to } \\
\text { family history of prostate cancer }\end{array}$} \\
\hline & CYP3A4-W & CYP3A4-V & CYP3A4-W & CYP3A4-V & CYP3A4-W & CYP3A4-V \\
\hline \multicolumn{7}{|c|}{$\begin{array}{l}\text { Earlier age at } \\
\quad \text { diagnosis, } \leqslant 63 \text { y }\end{array}$} \\
\hline $\mathrm{T} 1$ & $14(88 \%)$ & $2(12 \%)$ & $5(71 \%)$ & $2(29 \%)$ & $19(83 \%)$ & $4(17 \%)$ \\
\hline $\mathrm{T} 2$ & $31(74 \%)$ & $11(26 \%)$ & $17(89 \%)$ & $2(11 \%)$ & $48(79 \%)$ & $13(21 \%)$ \\
\hline \multirow[t]{2}{*}{$\mathrm{T} 3 / \mathrm{T} 4$} & $20(87 \%)$ & $3(13 \%)$ & $7(100 \%)$ & $0(0 \%)$ & $27(90 \%)$ & $3(10 \%)$ \\
\hline & \multicolumn{2}{|c|}{ FET $P=.401$} & \multicolumn{2}{|c|}{ FET $P=.369$} & \multicolumn{2}{|c|}{ FET $P=.411$} \\
\hline \multicolumn{7}{|c|}{ Later age at diagnosis, $>63 \mathrm{y}$} \\
\hline $\mathrm{T} 1$ & $20(95 \%)$ & $1(5 \%)$ & $6(100 \%)$ & $0(0 \%)$ & $26(96 \%)$ & $1(4 \%)$ \\
\hline $\mathrm{T} 2$ & $40(87 \%)$ & $6(13 \%)$ & $11(85 \%)$ & $2(15 \%)$ & $51(86 \%)$ & $8(14 \%)$ \\
\hline \multirow[t]{2}{*}{$\mathrm{T} 3 / \mathrm{T} 4$} & $13(54 \%)$ & $11(46 \%)$ & $4(67 \%)$ & $2(33 \%)$ & $17(57 \%)$ & $13(43 \%)$ \\
\hline & \multicolumn{2}{|c|}{ FET $P=.0008$} & \multicolumn{2}{|c|}{ FET $P=.507$} & \multicolumn{2}{|c|}{ FET $P=.0003$} \\
\hline \multicolumn{7}{|c|}{ Any age at diagnosis } \\
\hline $\mathrm{T} 1$ & $34(92 \%)$ & $3(8 \%)$ & $11(85 \%)$ & $2(15 \%)$ & $45(90 \%)$ & $5(10 \%)$ \\
\hline $\mathrm{T} 2$ & $71(81 \%)$ & $17(19 \%)$ & $28(88 \%)$ & $4(13 \%)$ & $99(83 \%)$ & $21(18 \%)$ \\
\hline \multirow[t]{2}{*}{$\mathrm{T} 3 / \mathrm{T} 4$} & $33(70 \%)$ & $14(30 \%)$ & $11(85 \%)$ & $2(15 \%)$ & $44(73 \%)$ & $16(27 \%)$ \\
\hline & \multicolumn{2}{|c|}{ FET $P=.049$} & \multicolumn{2}{|c|}{ FET $P=1.000$} & \multicolumn{2}{|c|}{ FET $P=.081$} \\
\hline
\end{tabular}

*TNM (tumor-lymph node-metastasis) stage [see (9)]; T1 = T1a-T1c, T2 = T2a-T2c, and T3/T4 = any $\mathrm{T} 3$ or T4 stage tumor.

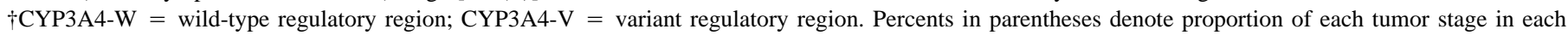
genotype class. FET = two-tailed Fisher's exact test.

tients diagnosed at a later age $(P=.0003$ $\left[\right.$ FET]; $\left.\chi^{2}{ }_{1}=14.81 ; P<.001\right)$, in those without a family history of prostate can$\operatorname{cer}\left(P=.049[\mathrm{FET}] ; \chi^{2}{ }_{1}=6.12 ; P=\right.$ $.013)$, or in those diagnosed at a later age and with a negative family history of prostate cancer $\left(P=.0008[\mathrm{FET}] ; \chi^{2}{ }_{1}=\right.$ 12.28; $P<.001)$. Age- and detection method-adjusted odds ratios from logistic regression approximated the relative risk of having a tumor of an advanced stage (T3/T4) associated with the CYP3A4-V genotype to be 2.10 (95\% confidence interval $[\mathrm{CI}]=1.09-4.05)$. The adjusted odds ratio estimates increased to 2.72 (95\% CI $=1.24-5.61)$ for patients with- out a family history of prostate cancer, to 6.70 (95\% CI $=2.54-17.69)$ for those diagnosed at a later age, and to $9.45(95 \%$ $\mathrm{CI}=2.54-35.17)$ for those without a family history of prostate cancer who were diagnosed at a later age.

By collapsing the data on stage in Table 1, we also evaluated the effect of genotype on nonpalpable (stage T1) and palpable (stages T2-T4) tumors. A marginally significant relationship between the presence of a CYP3A4-V allele and palpable disease remained in patients without a family history of prostate cancer $\left(P\right.$ value $=.060[$ FET $] ; \chi_{1}^{2}=4.02 ; P$ $=.045)$, and a significant association re- mained in patients who were diagnosed at a later age $\left(P=.023[\mathrm{FET}] ; \chi^{2}{ }_{1}=5.29\right.$; $P=.021)$. The adjusted odds ratio estimates in these groups were $4.42(95 \% \mathrm{CI}$ $=1.17-16.63$ ) for patients without a family history of prostate cancer and 8.34 (95\% CI $=1.06-65.58)$ for patients diagnosed at a later age. No relationship with genotype was observed in other groups of patients. This result may be explained in part by small sample sizes in some groups. In all analyses, identical inferences were obtained when the data were stratified by use of age cut points other than the median (e.g., at 60 and 65 years of age).

Table 2. Association of CYP3A4 genotype with combined Gleason grade and TNM stage in 230 incident prostate cancer patients

\begin{tabular}{|c|c|c|c|c|c|c|}
\hline \multirow[b]{2}{*}{ Grade/stage* } & \multicolumn{2}{|c|}{ No family history of prostate cancer $\dagger$} & \multicolumn{2}{|c|}{ Positive family history of prostate cancer $\dagger$} & \multicolumn{2}{|c|}{$\begin{array}{l}\text { All individuals without regard to } \\
\text { family history of prostate cancer } \dagger\end{array}$} \\
\hline & CYP3A4-W & CYP3A4-V & CYP3A4-W & CYP3A4-V & CYP3A4-W & CYP3A4-V \\
\hline \multicolumn{7}{|c|}{$\begin{array}{l}\text { Earlier age at } \\
\text { diagnosis, } \leqslant 63 \text { y }\end{array}$} \\
\hline Low & $15(88 \%)$ & $2(12 \%)$ & $4(67 \%)$ & $2(33 \%)$ & $19(83 \%)$ & $4(17 \%)$ \\
\hline \multirow[t]{2}{*}{ High } & $69(79 \%)$ & $18(21 \%)$ & $25(93 \%)$ & $2(7 \%)$ & $94(82 \%)$ & $20(18 \%)$ \\
\hline & \multicolumn{2}{|c|}{ FET $P=.516$} & \multicolumn{2}{|c|}{ FET $P=.142$} & \multicolumn{2}{|c|}{ FET $P=1.000$} \\
\hline \multicolumn{7}{|c|}{ Later age at diagnosis, $>63 \mathrm{y}$} \\
\hline Low & $11(100 \%)$ & $0(0 \%)$ & $5(100 \%)$ & $0(0 \%)$ & $16(100 \%)$ & $0(0 \%)$ \\
\hline \multirow[t]{2}{*}{ High } & $43(75 \%)$ & $14(25 \%)$ & $16(80 \%)$ & $4(20 \%)$ & $59(77 \%)$ & $18(23 \%)$ \\
\hline & \multicolumn{2}{|c|}{ FET $P=.103$} & \multicolumn{2}{|c|}{ FET $P=.549$} & \multicolumn{2}{|c|}{ FET $P=.035$} \\
\hline \multicolumn{7}{|c|}{ Any age at diagnosis } \\
\hline Low & $26(93 \%)$ & $2(7 \%)$ & $9(82 \%)$ & $2(18 \%)$ & $35(90 \%)$ & $4(10 \%)$ \\
\hline \multirow[t]{2}{*}{ High } & $112(78 \%)$ & $32(22 \%)$ & $41(87 \%)$ & $6(13 \%)$ & $153(80 \%)$ & $38(20 \%)$ \\
\hline & \multicolumn{2}{|c|}{ FET $P=.074$} & \multicolumn{2}{|c|}{ FET $P=.639$} & \multicolumn{2}{|c|}{ FET $P=.179$} \\
\hline
\end{tabular}

*Combined Gleason grade and TNM (tumor-lymph node-metastasis) stage is defined as: "Low" = T1a-T1c stage and Gleason grade <7; "High" = T2-T4 stage or T1 stage and Gleason grade $\geqslant 7$. Gleason grading is described in (8) and TNM staging in (9).

$\dagger \mathrm{CYP} 3 \mathrm{~A}-4-\mathrm{W}=$ wild-type regulatory region; CYP3A4-V = variant regulatory region. Percents in parentheses denote proportion of each tumor grade/stage in each genotype class. FET $=$ two-tailed Fisher's exact test. 
The CYP3A4-V genotype was also overrepresented in patients with tumors of higher Gleason grade who had no family history of prostate cancer and who were diagnosed at a later age. In this group, $13 \%$ of patients whose tumors had a Gleason grade of 6 or less carried the CYP3A4-V allele, compared with $24 \%$ of patients whose tumors were Gleason grade 7 or greater $\left(\chi_{1}^{2}=16.73 ; P=\right.$ $.010)$. However, we detected no significant effect of the CYP3A4 genotype on Gleason grade in the total sample, and there was no difference in the genotypespecific mean Gleason grade in any ageor family history-specific group. As shown in Table 2, the CYP3A4 genotype distinguished tumors defined simultaneously by stage and grade in patients diagnosed at a later age $(P=.035$ [FET]; $\left.\chi^{2}{ }_{1}=4.64 ; P=.031\right)$ and distinguished such tumors marginally significantly in patients without a family history of prostate cancer $\left(P=.074[\mathrm{FET}] ; \chi^{2}{ }_{1}=3.36\right.$; $P=.067)$ but did not distinguish tumors from patients in other groups. Again, identical inferences were obtained when analyses were undertaken with the use of age cut points other than the median. We conclude that the CYP3A4 genotype may have a greater effect on tumor stage than on Gleason grade.

\section{Discussion}

We identified a novel genetic variant in a $5^{\prime}$ regulatory element of the human CYP3A4 coding region and report that prostate cancer patients who carry this variant allele have tumors of a higher clinical stage than patients who do not carry this variant. The hypothesis that the Cyp3a4 protein may be involved in modifying the clinical presentation of prostate cancers is supported by knowledge about testosterone metabolism. The Сур3a4 protein is responsible for $2 \beta-, 6 \beta-$, and $15 \beta$-hydroxylation of testosterone, which may result in the hormone's functional deactivation $(4,12)$. The CYP3A4 allelic variant reported here is an alteration in a transcriptional regulatory element that may be required for CYP3A4 gene expression (10). We therefore hypothesize that men with CYP3A4-V genotypes may have decreased Cyp3a4 protein activity and, thus, decreased $2 \beta-, 6 \beta-$, and $15 \beta-$ testosterone oxidation. This decreased oxidation may in turn increase the bio- availability of testosterone for conversion to its intracellular mediator, dihydrotestosterone, the principal androgenic hormone involved in the regulation of prostate cell growth and function (13). Therefore, it is biologically plausible that the CYP3A4 allelic variant reported here may influence androgen-mediated prostate carcinogenesis and, thus, the presentation of prostate cancers.

We report that the effect of the CYP3A4 genotype on clinical presentation of prostate cancer is more pronounced in men diagnosed at an older age. In aging men, free testosterone levels decline moderately (14), and there is a possible shift in the distribution of testosterone metabolites, e.g., a decrease in $5 \alpha$ over $5 \beta$ metabolites (15). An explanation for this observation is that CYP3A4-V genotypes may be associated with increased testosterone bioavailability, which may be relatively more important in men who have lower basal testosterone levels (e.g., older men) than in men who have higher basal testosterone levels (e.g., younger men). In other words, having a CYP3A4-V genotype may be associated with relatively higher basal testosterone levels in older men, resulting in prostate cancers of higher stage than those occurring in older men who do not carry the variant allele.

There are two primary analytical limitations in this study. First, the sample size may have been too small to detect significant effects in some groups, particularly those with a family history of prostate cancer. Therefore, strong inferences cannot be made about the effect of the CYP3A4 genotype in individuals with a family history of prostate cancer. Second, numerous statistical tests were performed in the generation of the present results. In this hypothesis-generating study, we used a $P$ value of .05 for all statistical inferences. However, even after applying a more conservative significance level of .003 (i.e., $.05 / 18$, where 18 is the number of contingency table tests performed), we were still able to conclude statistical significance in the relationship between the CYP3A4 genotype and tumor stage in patients without a family history of prostate cancer and/or in those with late onset cancers (Table 1).

The identification of the CYP3A4 genotype as a biomarker associated with prostate cancer has potential implications for treatment and prevention of prostate cancer. First, knowledge about the CYP3A4 genotype may provide useful information about prostate cancer treatment or prognosis. It has been reported that the CYP3A4 enzyme is detectable in only $61 \%$ of prostate tumors (6), suggesting that there is tumor-specific variability in CYP3A4 gene expression. Therefore, response to hormone therapy may be in part determined by the CYP3A4 genotype or the Cyp3a4 phenotype. Our finding that stage at diagnosis is associated with genotype also implies that knowledge of the CYP3A4 genotype may be of value in evaluating prognosis, since prostate tumor stage is an important predictor of mortality from prostate cancer (16). Second, primary prostate cancer prevention strategies may be enhanced by knowledge about the CYP3A4 genotype. In addition to its effects on testosterone metabolism, the Cyp3a4 protein also oxidizes finasteride (17), an inhibitor of the $5 \alpha$-reductase involved in the formation of dihydrotestosterone. Since individuals who carry the CYP3A4-V allele may have increased activity in the testosterone-dihydrotestosterone pathway, the CYP3A4 genotype may influence an individual's response to prostate cancer chemoprevention by finasteride.

This case-case study design does not allow us to directly address the role of the CYP3A4 alleles in the etiology of prostate cancer. We are currently undertaking formal case-control studies of the CYP3A4 genotype for that purpose. Other genotypes have been identified previously that may be involved in the etiology of prostate cancer. For example, the HPC1 gene may explain a proportion of hereditary prostate cancers (18). Other genes involved in androgen metabolism have also been implicated in the etiology of prostate cancer. These include the androgen receptor, $5 \alpha$-reductase type II, and, possibly the $3 \alpha-, 3 \beta-$, and $17 \beta$-hydroxysteroid dehydrogenases $(1-3,19)$. In combination with our results, these studies suggest that multiple genes involved in androgen metabolism pathways may play a role in prostate cancer etiology.

\section{References}

(1) Giovannucci E, Stampfer MJ, Krithivas K, Brown M, Dahl D, Brufsky A, et al. The CAG repeat within the androgen receptor gene and 
its relationship to prostate cancer [published erratum appears in Proc Natl Acad Sci U S A 1997;94:8272]. Proc Natl Acad Sci U S A 1997;94:3320-3.

(2) Ingles SA, Ross RK, Yu MC, Irvine RA, La Pera G, Haile RW, et al. Association of prostate cancer risk with genetic polymorphisms in vitamin D receptor and androgen receptor. J Natl Cancer Inst 1997;89:166-70.

(3) Reichardt JK, Makridakis N, Henderson BE, Yu MC, Pike MC, Ross RK. Genetic variability of the human SRD5A2 gene: implications for prostate cancer risk. Cancer Res 1995;55: 3973-5.

(4) Waxman DJ, Attisano C, Guengerich FP, Lapenson DP. Human liver microsomal steroid metabolism: identification of the major microsomal steroid hormone $6 \beta$-hydroxylase cytochrome P-450 enzyme. Arch Biochem Biophys 1988;263:424-36.

(5) Kleinbloesem CH, van Brummelen P, Faber H, Danhof M, Vermeulen NP, Breimer DD. Variability in nifedipine pharmacokinetics and dynamics: a new oxidation polymorphism in man. Biochem Pharmacol 1984;33:3721-4.

(6) Murray GI, Taylor VE, McKay JA, Weaver RJ, Ewen SW, Melvin WT, et al. The immunohistochemical localization of drugmetabolizing enzymes in prostate cancer. $\mathbf{J}$ Pathol 1995;177:147-52.

(7) Richards B, Skoletsky J, Shuber AP, Balfour R, Stern RC, Dorkin HL, et al. Multiplex PCR amplification from the CFTR gene using DNA prepared from buccal brushes/swabs, Hum Mol Genet 1993;2:159-63.

(8) Gleason DF. The Veteran's Administration Cooperative Urologic Research Group: histo- logic grading and clinical staging of prostatic carcinoma. In: Tannenbaum M, editor. Urologic pathology: the prostate. Philadelphia: Lea \& Febiger; 1977. p 171-98.

(9) Beahrs OH, Henson DE, Hutter RV, Kennedy BJ, editors. Manual for staging of cancer. 4th ed. Philadelphia: Lippincott; 1992. p 185-6.

(10) Hashimoto H, Toide K, Kitamura R, Fujita M, Tagawa S, Itoh S, et al. Gene structure of CYP3A4, an adult-specific form of cytochrome P450 in human livers, and its transcriptional control. Eur J Biochem 1993;218: 585-95.

(11) Ganguly A, Rock MJ, Prockop DJ. Conformation-sensitive gel electrophoresis for rapid detection of single-base differences in doublestranded PCR products and DNA fragments: evidence for solvent-induced bends in DNA heteroduplexes [published erratum appears in Proc Natl Acad Sci U S A 1994;91:5217]. Proc Acad Nat Sci U S A 1993;90:10325-9.

(12) Waxman DJ, Lapenson DP, Aoyama T, Gelboin HV, Gonzalez FJ, Korzekwa K. Steroid hormone hydroxylase specificities of eleven cDNA-expressed human cytochrome P450s. Arch Biochem Biophys 1991;290:160-6.

(13) Coffey DS. Androgen action and the sex accessory tissues. In: Knobil E, Neill JJ, Ewing LL, editors. The physiology of reproduction. New York: Raven Press; 1988. p 1081-118.

(14) Vermeulen A. Androgens in male senescence. In: Nieschlag E, Behre HM, editors. Testosterone: action, deficiency, substitution. Berlin: Springer-Verlag; 1980. p 261-76.

(15) Vermeulen A, Verdonck L. Some studies on the biological significance of free testosterone. J Steroid Biochem 1972;3:421-6.
(16) Johansson JE, Holmberg L, Johansson S, Bergstrom R, Adami HO. Fifteen-year survival in prostate cancer. A prospective, populationbased study [published erratum appears in JAMA 1997;278:206]. JAMA 1997;277: 467-71.

(17) Huskey SW, Dean DC, Miller RR, Rasmusson $\mathrm{GH}$, Chiu SH. Identification of human cytochrome P450 isozymes responsible for the in vitro oxidative metabolism of finasteride [published erratum appears in Drug Metab Dispos 1996;24:695]. Drug Metab Dispos 1995;23: 1126-35.

(18) Smith JR, Freije D, Carpten JD, Gronberg H, $\mathrm{Xu}$ J, Isaacs SD, et al. Major susceptibility locus for prostate cancer on chromosome 1 suggested by a genome-wide search. Science 1996;274:1371-4.

(19) Devgan SA, Henderson BE, Yu MC, Shi CY, Pike MC, Ross RK, et al. Genetic variation of 3 beta-hydroxysteroid dehydrogenase type II in three racial/ethnic groups: implications for prostate cancer risk. Prostate 1997;33:9-12.

\section{Notes}

Supported by Public Health Service grants ES08031 (National Institute of Environmental Health Sciences) and CA73730 (National Cancer Institute), National Institutes of Health, Department of Health and Human Services (both grants to T. R. Rebbeck); and by the University of Pennsylvania Cancer Center.

Manuscript received January 27, 1998; revised May 11, 1998; accepted June 11, 1998. 